\title{
Validation of an interactive map assessing the potential spread of Galba truncatula as intermediate host of Fasciola hepatica in Switzerland
}

\author{
Rhea Baggenstos, ${ }^{1}$ Tobias Dahinden, ${ }^{2}$ Paul R. Torgerson, ${ }^{3}$ Hansruedi Bär, ${ }^{4}$ \\ Christina Rapsch, ${ }^{1}$ Gabriela Knubben-Schweizer ${ }^{1,5}$ \\ ${ }^{1}$ Department of Farm Animals, University of Zurich, Zurich, Switzerland; 'Institute of \\ Cartography and Geoinformatics, Leibniz University Hannover, Hannover, Germany; \\ ${ }^{3}$ Section of Veterinary Epidemiology, University of Zürich, Zürich; ${ }^{4}$ Institute of \\ Cartography and Geoinformation, Swiss Federal Institute of Technology in Zurich, Zurich, \\ Switzerland; ${ }^{5}$ Clinic for Ruminants with Ambulatory and Herd Health Services, Ludwig- \\ Maximilians-University Munich, Oberschleissheim, Germany
}

\begin{abstract}
Bovine fasciolosis, caused by Fasciola hepatica, is widespread in Switzerland. The risk regions were modelled in 2008 by an interactive map, showing the monthly potential risk of transmission of $F$. hepatica in Switzerland. As this map is based on a mathematical model, the aim of the present study was to evaluate the interactive map by means of a field survey taking different data sources into account. It was found that the interactive map has a sensitivity of $40.7-88.9 \%$, a specificity of $11.4-18.8 \%$, a positive predictive value of $26.7-51.4 \%$, and a negative predictive value of $13.1-83.6 \%$, depending on the source of the data. In conclusion, the grid of the interactive map $(100 \times 100 \mathrm{~m})$ does not reflect enough detail and the underlying model of the interactive map is lacking transmission data.
\end{abstract}

\footnotetext{
Correspondence: Gabriela Knubben-Schweizer, Clinic for Ruminants with Ambulatory and Herd Health Services, Ludwig-Maximilians-University, Munich Sonnenstrasse 16, D-85764 Oberschleissheim, Germany.

Tel: +49.89 .218078850 - Fax: +49.89 .218078851$

E-mail: G.Knubben@Imu.de
}

Key words: Fasciola hepatica; Galba truncatula; Risk modelling; Interactive map; Switzerland.

Acknowledgements: we thank Dr. phil. nat. Simon Capt (Centre Suisse de Cartographie da la Faune, CSCF) for providing the CSCF data.

Received for publication: 2 October 2015.

Revision received: 17 December 2015.

Accepted for publication: 18 December 2015.

CCopyright R. Baggenstos et al., 2016

Licensee PAGEPress, Italy

Geospatial Health 2016; 11:418

doi:10.4081/gh.2016.418

This article is distributed under the terms of the Creative Commons Attribution Noncommercial License (CC BY-NC 4.0) which permits any noncommercial use, distribution, and reproduction in any medium, provided the original author(s) and source are credited.

\section{Introduction}

Bovine fasciolosis, caused by Fasciola hepatica, is widespread in Switzerland. A study by Rapsch et al. (2006) estimated a true prevalence of $18.0 \%$ in slaughtered cattle of all age groups. Median financial losses, mainly due to reduced milk production and reduced fertility, are estimated at $€ 299$ per infected animal per year (Schweizer et al., 2005a). Nevertheless, farmers often are unaware of the disease (Schweizer et al., 2005b). In order to enhance awareness among owners and give farmers and veterinarians a decision-making tool for investigating a herd for fasciolosis, an interactive map was designed, showing the monthly potential risk of transmission of $F$. hepatica in Switzerland (Rapsch et al., 2008). The interactive map is based on risk density distribution derived from environmental factors. Geographical (soil condition, forest cover) and meteorological (temperature, rainfall) data from Switzerland and biological data of the intermediate host Galba truncat$u l a$ and the free-living stages of $F$. hepatica were accounted for. The model's output is an environmental relative risk measurement for the development of $G$. truncatula and the free-living stages of $F$. hepatica all over Switzerland. In order to visualise the density distribution, a grid of $100 \times 100$ m cells was created for the whole country and the risk density for each cell of the grid was visualised by a colour scale ranging from highest (red) to no (white) risk, representing five risk classes. The elements of the map (canton boundaries, water bodies, landform configuration, cities, forest, monthly risk, risk during the year) are grouped in layers, which can be activated or deactivated. Maps produced by means of geographical information systems (GIS) are often used in human or veterinary medicine in order to identify epidemiological patterns of disease outbreaks for example. GIS is especially helpful when trying to answer epidemiological questions concerning vector borne diseases or diseases transmitted by intermediate hosts (Rinaldi et al., 2006) and with increasing technical possibilities, the number of studies using GIS has also increased (Hendrickx et al., 2004; Simoonga et al., 2009). Risk maps for the transmission of $F$. hepatica have been designed for parts of Europe (Ollerenshaw, 1966; Rapsch et al., 2008), parts of the United States (Malone et al., 1987, 1992), Ethiopia (Yilma and Malone, 1998) or Cambodia (Tum et al., 2004). Some of the models were validated mainly by means of definite host prevalence surveys (Malone et al., 1992; Malone and Gommes, 1998; Tum et al., 2007).

The aim of the present study was to evaluate the interactive map by means of a field survey based on the presence or absence of suitable snail habitats and presence of snails. 


\section{Materials and Methods}

In order to evaluate the risk model, findings of potential $G$. truncatula habitats and snail findings from three data sources were used and then compared to the risk map.

\section{Data sources}

\section{Snail findings emanating from a field survey in $\mathbf{2 0 1 0}$}

The basis of the interactive map designed by Rapsch et al. (2008), covering the whole of Switzerland, is a $100 \times 100 \mathrm{~m}$ grid (containing a total of 4'152'874 grid fields). During a field survey in 2010, 361 grid fields were searched for the presence of potential $G$. truncatula habitats deriving from 80 coordinate points in the Northeast of Switzerland chosen by a random generator (Java Random). Water bodies, forests and settlements were excluded. The region was chosen due to ease of surveillance (location of the Vetsuisse Faculty, Zurich) on the one hand and due to the overlapping with the study region surveyed by Schweizer et al. (2007) on the other. The field survey was conducted from July to October 2010 . The 80 randomly chosen points were visited and the minimal area of $100 \times 100 \mathrm{~m}$ was investigated including the randomly chosen point. Due to the topography and the landscape, it was not possible to set up identical investigation areas, so the randomly chosen coordinate points did not always lie in the middle of the investigation area but were always included. If the $100 \times 100 \mathrm{~m}$ area around the randomly chosen coordinate points was dry and no evidence for potential $G$. truncatula habitats could be seen nearby, the investigation was stopped recording this area as negative. If the area around the randomly chosen point included potential habitats, e.g. drainage ditches, swampy areas or small streams as described by Schweizer et al. (2007), the coordinates of the potential habitats were recorded using a global positioning system (GPS) device (Garmin eTrex H) and the potential habitats were searched for snails for 30 minutes. This was usually an area of more than $100 \times 100 \mathrm{~m}$ (Figure 1). Snails found were collected and frozen at $-20^{\circ} \mathrm{C}$ until further identification by binocular loupe.

\section{Earlier snail findings}

From a regional survey in northeastern Switzerland investigating the prevalence of $F$. hepatica in the intermediate host, the coordinates of naturally occurring habitats were taken. Wells were excluded, as these are man-made habitats. The field surveys were conducted from 1999 to 2002 in the months of May to October. A total of 54 habitat findings in the Northeast of Switzerland were taken from the study of Schweizer et al. (2007).

\section{Snail findings emanating from the Centre Suisse de Cartographie de la Faune}

From 1990 to 2010 a total of 749 G. truncatula findings from all over Switzerland was registered by the Centre Suisse de Cartographie de la Faune (CSCF). The snails were found in all months of the year. of these, 66 findings had to be excluded due to incomplete recording of the coordinates and 236 findings were excluded because they were derived from forest or settlement areas. In such areas, cattle are not usually grazed and therefore the model gives no risk for transmission (Rapsch et al., 2008). Repeated findings in one month were utilised once. From the CSCF data a total of 428 findings were taken.

\section{Comparison of the risk map with the field survey data}

For the study at hand, the risk class 0 of the map created by Rapsch et al. (2008) was defined as no risk and the risk classes 1 to 5 were summarised as risk. In order to calculate the sensitivity, specificity,

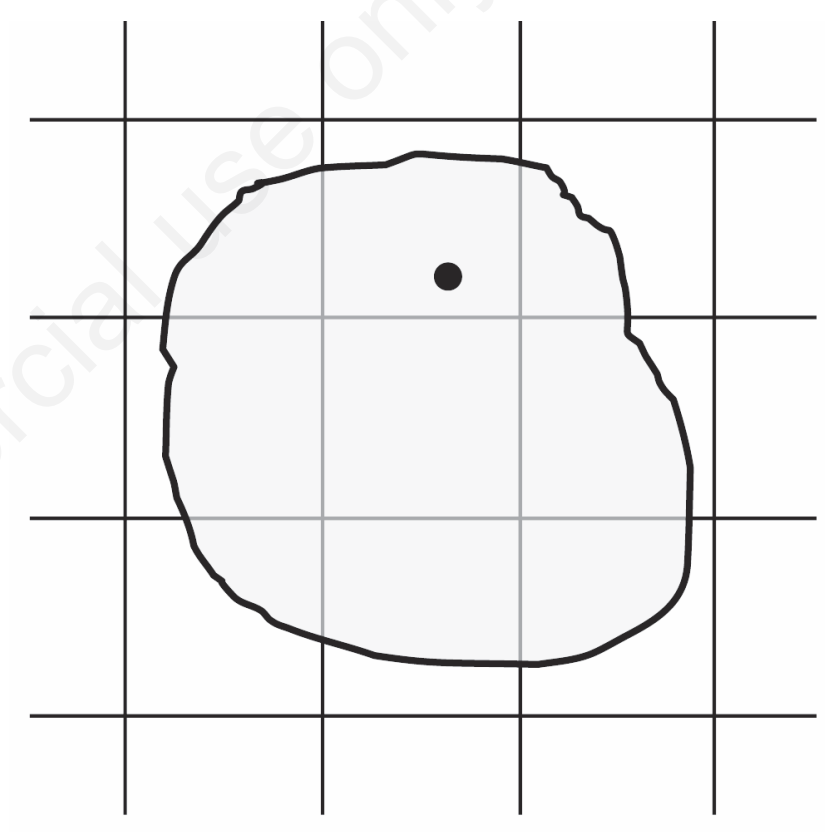

Figure 1. A diagram of the investigated area (grey) around a randomly chosen starting point $(\bullet)$. Underlying is the $100 \mathrm{~m} \times 100 \mathrm{~m}$ grid from the interactive map. In this example a total of 9 grid cells were investigated.

Table 1. Data sources for the evaluation of the original interactive map.

\begin{tabular}{|c|c|c|}
\hline Data source & Subject & Information \\
\hline Field survey 2010 & $\begin{array}{l}\text { Randomly chosen fields from } \\
\text { Northeast Switzerland ( } \mathrm{n}=361)\end{array}$ & $\begin{array}{l}\text { 1. Fields without risk of transmission (no potential habitats) } \\
\text { 2. Fields with potential risk of transmission } \\
\text { 2.1. without } G \text {. truncatula } \\
\text { 2.2. with } G \text {. truncatula }\end{array}$ \\
\hline Schweizer et al. (2007) & G. truncatula findings from Northeast Switzerland ( $\mathrm{n}=54)$ & Potential risk of transmission \\
\hline CSCF & G. truncatula findings from all over Switzerland $(\mathrm{n}=428)$ & Potential risk of transmission \\
\hline
\end{tabular}

G. truncatula, Galba truncatula; CSCF, Centre Suisse de Cartographie de la Faune. 
positive and negative predictive value of the map, the snail searches from three different surveys from Switzerland (Table 1) were then compared to the map predicted risk (no risk vs risk). As the interactive map models potential habitats of $G$. truncatula on a monthly basis, the evaluation of the map also takes the month of finding into account. The investigated fields from the field surveys were either classified negative, when no potential habitats were found or positive when either potential habitats (without snails) or habitats with snails were found (Table 2). All coordinates were rounded to the next $100 \mathrm{~m}$ interval, in order to match the $100 \times 100 \mathrm{~m}$ grid of the interactive map. Subsequently, the monthly risk groups of the investigated areas were taken from the model. Multiple coordinates lying in one grid area were utilised once.

The sensitivity, i.e. the true positives divided by the true positives + the false negatives; specificity, i.e. the true negatives divided by the true negatives + the false positives; the positive predictive value, i.e. the true positives divided by the true positives + false positives; and the negative predictive value, i.e. the true negative divided by the true negatives + false negatives were calculated for the map.

Two different calculations were made in order to achieve the sensitivity, specificity and the predictive values of the interactive map. First, from all data sources the true monthly findings were compared to the modelled monthly risk group, e.g. the findings in January were compared to the January risk model. Second, from all data sources only the findings from July, August, September, and October were taken. During these months the field survey in 2010 took place. The data from July and August were then compared to the corresponding monthly risk model, whereas the data from September and October were compared to the August risk model as this model predicts the largest risk areas. As the overall model is lacking an underlying transmission model, we assumed, that the areas with the best environmental conditions for the survival and reproduction of $G$. truncatula, and the survival of the freeliving stages of $F$. hepatica, in August would also have a higher risk for transmission in the following months (taking the lag of time for reproduction of the snail into account).

\section{Results}

\section{Classification of the grid fields}

From the field survey in 2010, 271 grid fields did not contain potential habitats and were therefore negative areas. Potential habitats (positive) were found in 90 grid fields. Out of these, 14 harboured a total of 133 G. truncatula specimens. A total of 89 snails were found in risk class 1 (66.9\%), two in risk class 2 (1.5\%), four in risk class $3(3.0 \%)$, 28 in risk class 4 (21.1\%) and 10 in risk class 5 (7.5\%). The potential habitats in risk class 0 did not contain any $G$. truncatula specimens. Together with the findings from Schweizer et al. (2007) and the CSCF, a total of 496 grid fields with $G$. truncatula specimens was found.

\section{Validity of the interactive map}

Validity based on the findings from the field survey 2010 compared per month

In 76 grid fields, consisting of swampy areas, ditches and other humid biotopes, no $G$. truncatula specimens were found. Nevertheless, these grid fields were classified positive, as they serve as potential habitats. When comparing the monthly-modelled risk class to the actual findings in the field (Table 3), the sensitivity of the interactive map was $88.9 \%$, the specificity $18.8 \%$, the positive predictive value $26.7 \%$ and the negative predictive value $83.6 \%$.

\section{Validity based on the findings of all data compared per month}

When comparing the monthly-modelled risk groups with the actual findings in the field (Table 4), the sensitivity of the interactive map was $40.7 \%$, the specificity $18.8 \%$, the positive predictive value $51.4 \%$ and the negative predictive value $13.0 \%$.

Validity based on the findings of all data from July to October

When comparing the findings from all sources from July to October

Table 2. Classification of results of the field surveys compared to the risk model.

\begin{tabular}{lcc} 
Interactive map & \multicolumn{1}{c}{ Field survey } & \\
& Positive (presence of potential habitats) & Negative (absence of potential habitats) \\
Risk (risk class 1 to 5$)$ & True positive & False positive \\
No risk (risk class 0$)$ & False negative & True negative \\
\hline
\end{tabular}

Table 3. Comparison of results of the field survey 2010 with the risk classes in the model (interactive map) per month.

\begin{tabular}{lcc} 
Interactive map & $\begin{array}{c}\text { Findings from the field survey 2010 } \\
\text { Number of positive grid fields* }(\%)\end{array}$ \\
Risk class 0 & $51(18.8)$ & $10(11.1)$ \\
Risk class 1 & $34(12.6)$ & $28(31.1)$ \\
\hline Risk class 2 & $33(12.2)$ & $12(13.3)$ \\
Risk class 3 & $31(11.4)$ & $11(12.2)$ \\
\hline Risk class 4 & $38(14.0)$ & $5(5.6)$ \\
Risk class 5 & $84(31.0)$ & $24(26.7)$ \\
\hline Risk class 1-5 & $220(81.2)$ & $80(88.9)$ \\
Total & $271(100)$ & $90(100)$ \\
\hline
\end{tabular}

Negative grid fields, grid fields without potential habitats; positive grid fields, grid fields with potential habitats either with snails or without (but with typical vegetation). 
(Table 5) compared to the modelled risk maps July to October, the sensitivity was $53.7 \%$, the specificity $18.8 \%$, the positive predictive value $46.5 \%$ and the negative predictive value $23.6 \%$. When comparing the findings from all sources from July and August (Table 6) compared to the corresponding risk model and the findings from September and October compared to the August risk model (Figure 2) the sensitivity was $65.2 \%$, the specificity is $11.4 \%$, the positive predictive value is $49.2 \%$ and the negative predictive value $20.0 \%$.

\section{Discussion}

The interactive map of Rapsch et al. (2008) models areas with suitable environmental conditions for the survival and reproduction of $G$. truncatula, including survival of the free-living stages of $F$. hepatica. The risk areas modelled are corroborated by a study by Ducheyne $e t$ al. (2015) modelling the spatial distribution of $F$. hepatica in dairy cattle in Europe, including Switzerland.

The aim of the present study was to evaluate the risk map from Rapsch et al. (2008) by comparing the modelled risk areas with find- ings from different field surveys with respect to the main intermediate host snail $G$. truncatula of $F$. hepatica. This approach was chosen because the risk map models the potential spread of $G$. truncatula and not the spread of $F$. hepatica itself (except its free-living stages). In comparable studies, risk maps are evaluated by cattle prevalence data (Malone et al., 1992; Malone and Gommes, 1998; Tum et al., 2007). In Switzerland there is excessive movement of animals, especially of young stock going to alpine pastures during the summer months. If these first and second summer grazing animals become infected with F. hepatica, they will shed eggs and secrete antibodies into their first and second lactation (Knubben-Schweizer and Torgerson, 2015). Positive results of bulk milk antibody tests are therefore not necessarily indicative for a new infection on the premise in question but it can be derived from very different geographical regions. It would therefore be more appropriate to search for potential snail habitats and snails than to compare the risk map to prevalence data in cattle.

The search for potential snail habitats and snails poses several challenges. Even though typical habitats, as described by Schweizer et al. (2007), with putative suitable environmental conditions may be present, $G$. truncatula can still be absent. To the authors' experience, this is especially true, when habitats are visited once only as the size of the

Table 4. Comparison of results of the monthly risk models (interactive map) with the results of the field surveys from January to December.

\begin{tabular}{|c|c|c|c|}
\hline Interactive map & & & Total \\
\hline & Positive & Negative & \\
\hline Risk (risk class 1-5) & 233 & 220 & 453 \\
\hline No risk (risk class 0 ) & 339 & 51 & 390 \\
\hline Total & 572 & 271 & 843 \\
\hline
\end{tabular}

Positive, presence of potential habitats either with snails or without (but with typical vegetation); negative, absence of potential habitats. ${ }^{\circ}$ Field survey 2010, data from Schweizer $e t$ al. (2007) and findings from Centre Suisse de Cartographie de la Faune.

Table 5. Comparison of results of the monthly risk models (interactive map) with the results of the field surveys from July to October.

\begin{tabular}{lcccc} 
Interactive map & \multicolumn{3}{c}{$\begin{array}{c}\text { Classification of the grid fields based on the } \\
\text { field surveys }\end{array}$} \\
& Positive & Nom July to October & Notal \\
Risk (risk class 1-5) & 191 & 220 & 411 \\
No risk (risk class 0) & 165 & 21 & 216 \\
\hline Total & 356 & 271 & 627
\end{tabular}

Positive, presence of potential habitats either with snails or without (but with typical vegetation); negative, absence of potential habitats. ${ }^{\circ}$ Field survey 2010, data from Schweizer et al. (2007) and findings from Centre Suisse de Cartographie de la Faune.

Table 6. Comparison of the findings from all sources in July and August compared to the corresponding risk model and the findings from all sources from September and October compared to the August risk model.

\begin{tabular}{|c|c|c|c|}
\hline \multirow[t]{2}{*}{ Interactive map } & \multicolumn{2}{|c|}{$\begin{array}{l}\text { Classification of the grid fields based on the } \\
\text { field surveys }{ }^{\circ} \text { from July to October }\end{array}$} & \multirow[t]{2}{*}{ Total } \\
\hline & Positive & Negative & \\
\hline Risk (risk class 1-5) & 232 & 240 & 472 \\
\hline No risk (risk class 0 ) & 124 & 31 & 155 \\
\hline Total & 356 & 271 & 627 \\
\hline
\end{tabular}

Positive, presence of potential habitats either with snails or without (but with typical vegetation); negative, absence of potential habitats. Findings from September and October are compared to the August model.

${ }^{\circ}$ Field survey 2010, data from Schweizer et al. (2007) and findings from Centre Suisse de Cartographie de la Faune. 
snail population depends on the cumulative environmental conditions of the previous months. For this reason, not only snail findings were assessed as positive but also potential habitats as can be seen in Figures 3 to 5 .

Another challenge is the identification of the snails. Those from the present study and from Schweizer et al. (2007) were identified by an experienced person by macroscopic inspection. In questionable cases (e.g. very small snails) the identification took place under a binocular loupe. For the data from CSCF, the way the snails were identified is unknown. Misidentification cannot be ruled out, especially for very small snails.

In the current study, the infection status of the snails was not investigated as it was not of primary interest. In the study of Schweizer et al. (2007), the snails were examined using PCR to detect $F$. hepatica infection finding 7.0\% of 4733 snails positive. The risk of infection of $G$. truncatula with $F$. hepatica depended on the source of the snails (type of habitat and type of pastured cattle, respectively).

Another challenge in this field survey was that it was not always possible to survey the grid fields due to limitations, such as slope, water
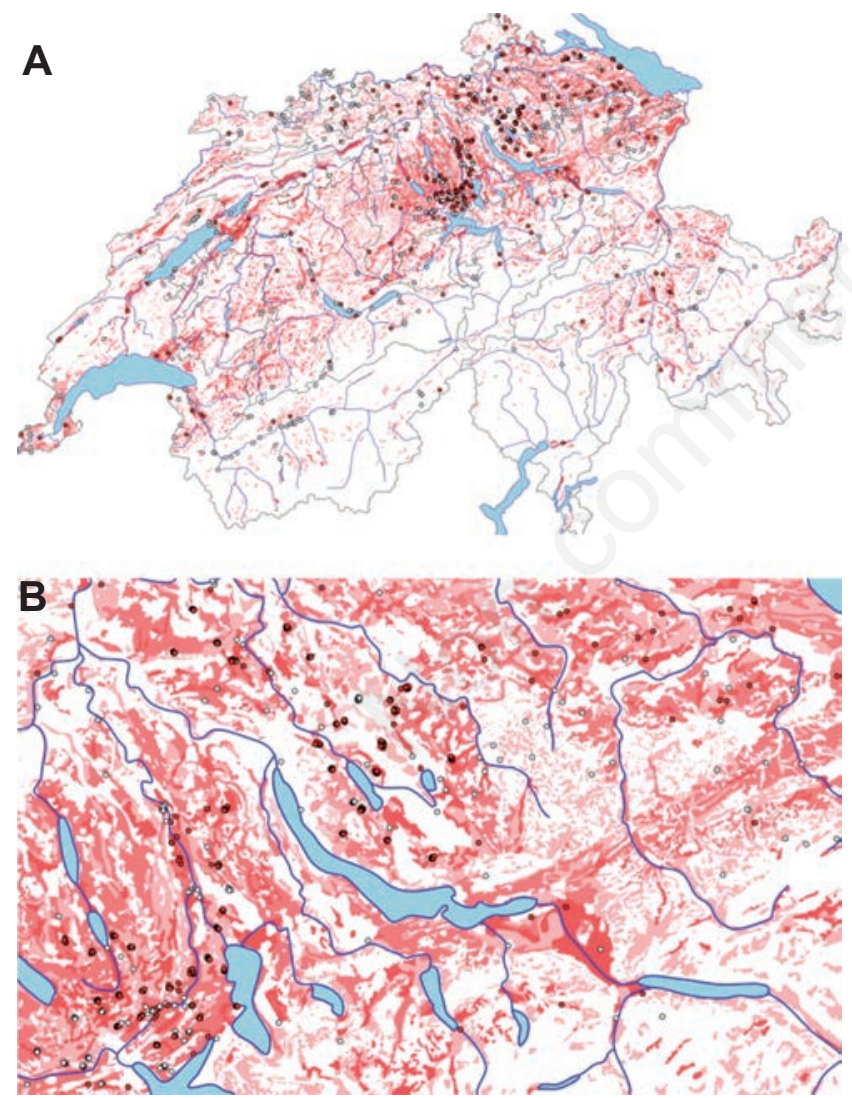

Figure 2. A) Risk map for the transmission of Fasciola hepatica in Switzerland. B) Detail of figure 2A: Northeast of Switzerland, where the survey at hand has been conducted. The risk for the month of August is shown. White areas are no risk (risk class 0), red shaded areas are risk (risk class 1 to 5). Additionally, the findings of Galba truncatula searches from 3 sources can be seen, where the red dots are positive findings (either potential habitats or snails) and the white dots are areas, with no potential snail habitats. course, street, building, land use etc. In such areas, it was therefore decided to choose a coordinate point and search the area around it. In the model, the surveyed area was then mapped and the number of grid fields covered by this area were analysed.

Several approaches were used to calculate the sensitivity, specificity

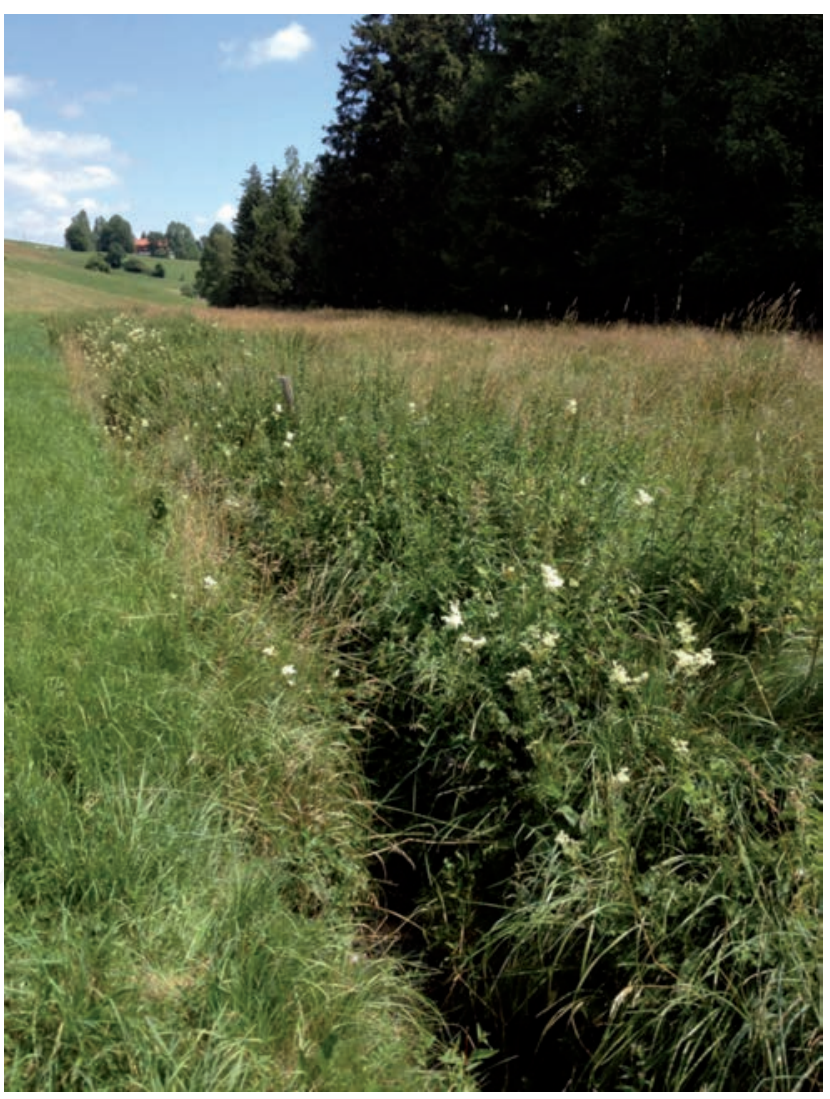

Figure 3. Drainage ditch in a swampy area making a potentially suitable habitat for Galba truncatula.

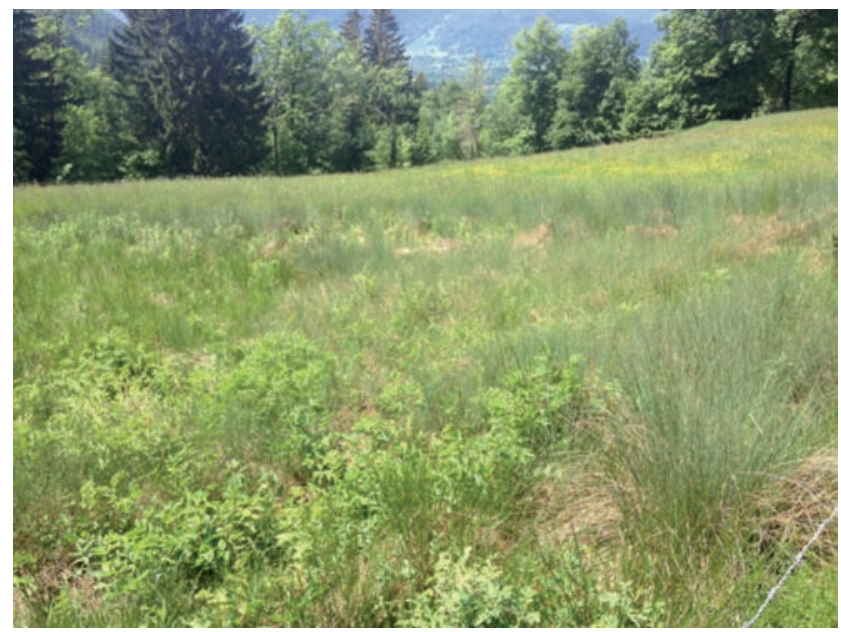

Figure 4. A swampy area making a potentially suitable habitat for Galba truncatula; notice the rush as an indicator plant described by Rondelaud et al. (2011). 


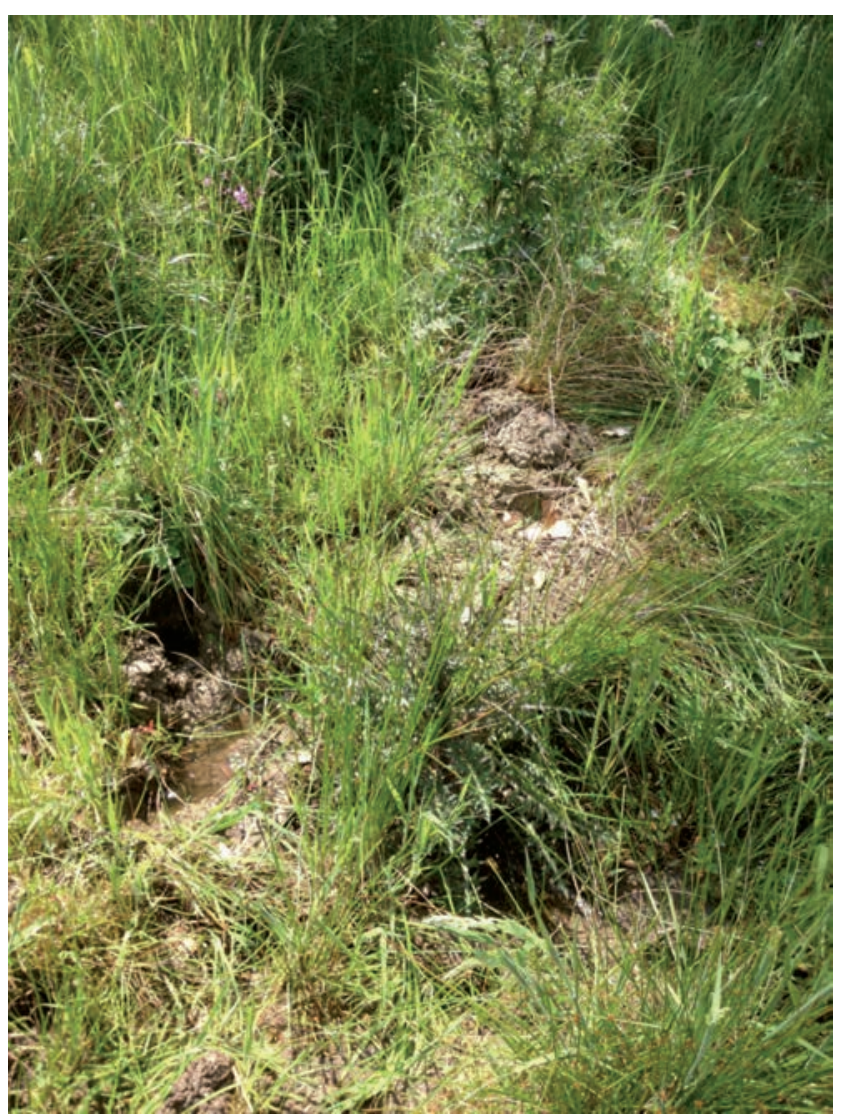

Figure 5. Spring water making a potentially suitable habitat for Galba truncatula.

and predictive values of the interactive map. In general the model is neither very sensitive nor very specific. When comparing the monthly findings of all surveys with the monthly risk models, $40.7 \%$ of the modelled risk areas habitats were found. Additionally, in the field survey of 2010 , only $18.8 \%$ of the areas of risk class 0 were without potential habitats and snails were not found in any of them. The chance of finding a potential habitat in an area where a risk is predicted by the model was $51.4 \%$ for any month of the year. In contrast, the chance of absence of habitats in an area where no risk was predicted by the model was $13.0 \%$ for any month of the year. Considering the conditions of the previous months when calculating the risk, these results were improved. Nevertheless, the sensitivity, specificity, positive and negative predictive values remained low.

As the interactive map lacks an underlying transmission model, mean monthly temperatures below $10^{\circ} \mathrm{C}$ result in a risk 0 classification of the affected grid field. For this reason, the interactive map does not predict any potential risk areas for the survival and reproduction of $G$. truncatula, and for the survival of the free-living stages of $F$. hepatica, during the winter months. Nevertheless, snails can overwinter and can therefore be found the whole year around (Mehl, 1932). As a result, the snails found from November to March, where the map does not show any risk areas at all, will lead to a decrease of the sensitivity and the negative predictive value for the 12-month-model.

A limitation of the interactive map is the grid size. Even though 100 $\mathrm{x} 100 \mathrm{~m}$ allows a resolution approaching the farm level, habitats are often much smaller. Swampy areas, drainage ditches and slow streams, which are the typical habitats for G. truncatula (Mehl, 1932; Schweizer et al., 2007) are not mapped on commercial maps (topographic map 1:25'000). This was considered by modelling the soil type (Wilson et al., 1982 ) in the interactive map based on the fact, that the water content is dependent on water permeability and how waterlogged it is (Rapsch et al., 2008). Furthermore, beside natural habitats, there are also manmade habitats, such as wells. Where the type of habitat was known, the wells were eliminated from the evaluation. Nevertheless, local microclimatic factors and ground condition as well as man-made habitats are almost impossible to model. Besides, habitats may vary over the years. As the study at hand was based on data deriving from a 20-year period (1990 to 2010), some alteration in habitats might have occurred. Another type of small habitat, also not considered in the interactive map, are areas characterised by spring water that generally occur on slopes. It was therefore assumed, that the implementation of small watercourses and slopes might increase the sensitivity, specificity and predictive values of the interactive map.

\section{Conclusions}

Models such as those assessing the potential spread of $G$. truncatula or the spatial distribution of $F$. hepatica can be very helpful tools for farmers and veterinarians. However, these are theoretical models. In order to validate the original Swiss model (Rapsch et al., 2008), a fieldsurvey was undertaken. This demonstrated moderate sensitivity, specificity and predictive values of the model. The next-step revision of the model will require the environmental factors to be examined in more detail (e.g. the role of slopes). Furthermore, a transmission model is in progress, which will be integrated into the map and help to reduce the problem of missing cumulative effects over the year.

\section{References}

Ducheyene E, Charlier J, Vercruysse J, Rinaldi L, Biggeri A, Demeler J, Brandt C, de Waal T, Selemetas N, Höglund J, Kaba J, Kowalczyk J, Hendrickx G, 2015. Modelling the spatial distribution of Fasciola hepatica in dairy cattle in Europe. Geospat Health 9:261-70.

Hendrickx G, Biesemans J, De Deken R, 2004. The use of GIS in veterinary parasitology. In: Durr P, Gatrell A, eds. GIS and spatial analysis in veterinary science. CABI Publishing, Wallingford, UK, pp 145-76.

Knubben-Schweizer G, Torgerson PR, 2015. Bovine fasciolosis: control strategies based on the location of Galba truncatula habitats on farms. Vet Parasitol 208:77-83.

Malone JB, Fehler DP, Loyacano AF, Zukowski SH, 1992. Use of LANDSAT MSS imagery and soil type in a geographic information system to assess site-specific risk of fascioliasis on Red River Basin farms in Louisiana. Ann NY Acad Sci 653:389-97.

Malone JB, Gommes R, 1998. A geographic information system on the potential distribution of Fasciola hepatica an $F$. gigantic in east Africa based of Food and Agriculture Organization database. Vet Parasitol 78:87-101.

Malone JB, Williams TE, Muller RA, Geaghan JP, Loyacano AF, 1987. Fascioliasis in cattle in Louisiana: development of a system to predict disease risk by climate, using the Thornthwaite water budget. Am J Vet Res 48:1167-70.

Mehl S, 1932. Die Lebensbedingungen der Leberegelschnecke (Galba truncatula Müller). Untersuchungen über Schale, Verbreitung, Lebensgeschichte, natürliche Feinde und Bekämpfun- 
gsmöglichkeiten. Dr. F.P. Datterer \& Cie Publ., Munich, Germany.

Ollerenshaw CB, 1966. The approach to forecasting the incidence of fascioliasis over England and Wales. Agr Meteorol 3:35-53.

Rapsch C, Dahinden T, Heinzmann D, Torgerson PR, Braun U, Deplazes P, Hurni L, Bär H, Knubben-Schweizer G, 2008. An interactive map to assess the potential spread of Lymnaea truncatula and the freeliving stages of Fasciola hepatica in Switzerland. Vet Parasitol 154:242-9.

Rapsch C, Schweizer G, Grimm F, Kohler L, Deplazes P, Braun U, Bauer C, Torgerson PR, 2006. Estimating the true prevalence of Fasciola hepatica in cattle slaughtered in Switzerland in the absence of an absolute diagnostic test. Int J Parasitol 36:1153-8.

Rinaldi L, Musella V, Biggeri A, Cringoli G, 2006. New insights into the application of geographical information systems and remote sensing in veterinary parasitology. Geospat Health 1:33-47.

Rondelaud D, Hourdin P, Vignoles P, Dreyfuss G, Cabaret J, 2011. The detection of snail host habitats in liver fluke infected farms by use of plant indicators. Vet Parasitol 181:166-73.

Schweizer G, Braun U, Deplazes P, Torgerson PR, 2005a. Estimating the financial losses due the bovine fasciolosis in Switzerland. Vet Rec 157:188-93.

Schweizer G, Hässig M, Braun U, 2005b. Das Problembewusstsein von Landwirten in Bezug auf die Fasciolose des Rindes. Schweiz Arch
Tierheilk 147:253-7.

Schweizer G, Meli ML, Torgerson PR, Lutz H, Deplazes P, Braun U, 2007. Prevalence of Fasciola hepatica in the intermediate host Lymnaea truncatula detected by real time TaqMan PCR in populations from 70 Swiss farms with cattle husbandry. Vet Parasitol 150:164-9.

Simoonga C, Utzinger J, Brooker S, Vounatsou P, Appleton CC, Stensgard AS, Olsen A, Kristensen TK, 2009. Remote sensing, geographical information system and spatial analysis for schistosomiasis epidemiology and ecology in Africa. Parasitology 136:1683-93.

Tum S, Puotinen ML, Copeman DB, 2004. A geographic information system model for mapping risk of fasciolosis in cattle and buffaloes in Cambodia. Vet Parasitol 122:141-9.

Tum S, Puotinen ML, Skerratt LF, Chan B, Sothoeun S, 2007. Validation of a geographic information system model for mapping the risk of fasciolosis in cattle and buffaloes in Cambodia. Vet Parasitol 143:364-7.

Wilson RA, Smith G, Thomas MR, 1982. Fascioliasis. In: Anderson RM, ed. The population dynamics of infectious diseases: theory and applications. Chapman and Hall, London, UK, pp 262-319.

Yilma JM, Malone JB, 1998. A geographic information system forecast model for strategic control of fasciolosis in Ethiopia. Vet Parasitol 78:103-27. 